\section{Biomechanical properties of the rectovaginal fascia. Is it really a fascia?}

\author{
Karin Glavind, ${ }^{1}$ Janus B. Jespersen, ${ }^{1}$ \\ Mikkel Seyer-Hansen ${ }^{2}$ \\ 'Department of Gynecology and \\ Obstetrics, Aalborg Sygehus Nord, \\ Aalborg; \\ 2Department of Gynecology and \\ Obstetrics, Århus University Hospital, \\ Århus N, Denmark
}

\section{Abstract}

Background. The aim of this study was to find out whether the rectovaginal fascia was really a true fascia by comparing the mechanical properties and collagen content of the rectovaginal fascia in women operated for rectoceles to the abdominal fascia in patients having an abdominal hysterectomy.

Materials and Methods. Thirty patients were included. During operation for rectocele or hysterectomy a biopsy measuring $8 \times 15 \mathrm{~mm}$ was taken from the rectovaginal fascia or abdominal fascia. Mechanical testing and measurement of collagen content was performed.

Results. A significant difference in mechanical strength of the tissue was found. If, however, the strength was corrected for collagen content there was no difference between the two groups.

Conclusion. The quality of collagen was comparable in the two groups. This adds further evidence to the existence of a distinct rectovaginal fascia.

\section{Introduction}

Since years, an ongoing discussion concerning the existence of a rectovaginal fascia between vagina and rectum is taking place. Some authors detect and repair the specific site defect in the rectovaginal fascia, ${ }^{1-4}$ while others deny the existence of a distinct rectovaginal fascia. $^{5}$

Ludwikowski et al. added important information to the controversy on the existence of the rectovaginal fascia by examining specimens from 31 female and 31 male newborns. ${ }^{6}$ The rectovaginal fascia was found as early as 12 weeks of gestational age and was clearly defined in all fetuses. In a study on embalmed and fresh female cadavers Leffler $\mathrm{et} \mathrm{al}$. found a well-defined rectovaginal fascia attaching to the pelvic sidewall along a well-defined line supporting the posterior compartment analogous to the fascia in the anterior compartment. ${ }^{7}$ Nagata et al. examined 20 female cadavers and found an elastic fiber-rich plate between the rectum and vagina in all cadavers. The fascia was often thin and interrupted and not so clearly demonstrated in the upper vagina. ${ }^{8}$ During laparoscopic dissection for surgical treatment of rectal cancer, Liang et al. found a very distinct fascia, Denonvilliers' fascia, in the male patients and a much less obvious fascia in female patients where they termed it the rectovaginal septum. ${ }^{9}$ The aim of this study was to compare the biomechanical properties and collagen content of the rectovaginal fascia to a well-known fascia, namely the abdominal fascia, to find out whether the rectovaginal fascia was a true fascia.

\section{Materials and Methods}

Thirty patients were included, 15 patients in group 1 (hysterectomy patients) and 15 patients in group 2 (rectocele patients). No power-calculation was performed as we did not seek to find a statistical difference between the two groups, but only to investigate whether the two fasciae were comparable. The study was approved by the local ethics committee.

During the operation for a rectocele a biopsy measuring approximately $8 \times 15 \mathrm{~mm}$ was removed from the rectovaginal fascia. The biopsy was taken in the area where the specific site defect was found before closing the defect. The patients were operated with a standard colporrhaphia posterior where the specific site defects were repaired. In patients undergoing standard abdominal hysterectomy for benign conditions a similar biopsy was taken from the abdominal fascia.

The biopsies from the patients were wrapped in plastic film and stored at $-18^{\circ} \mathrm{C}$ until mechanical testing. Two standardized specimens from each biopsy were cut out longitudinally with an instrument in which two razor blades were mounted $5 \mathrm{~mm}$ apart. The test procedure has been described in detail previously. ${ }^{10}$ The specimens were carefully prepared for testing and were mounted horizontally in a materials testing machine (modified Alwetron TCT 5, Lorenzen and Wettre, Stockholm, Sweden), and stretched at a constant speed of $10 \mathrm{~mm} / \mathrm{min}$ until failure (Figure 1). The load (force) and deformation (elongation) were measured continuously and transformed into load-strain curves. Strain values were expressed as deformation values per unit of the original length. The following parameters were obtained: maximum load, strain at maximum load and stiffness.

After mechanical testing the specimens were freeze-dried and defatted by acetone, defatted
Correspondence: Dr. Karin Glavind, Department of Gynecology and Obstetrics, Aalborg Sygehus Nord, 9000 Aalborg, Denmark.

Tel. +45.99321900 .

E-mail: glavind@dadlnet.dk

Key words: rectovaginal fascia, biomechanics, collagen.

Contributions: all authors contributed equally to the manuscript.

Conflict of interest: the authors report no conflicts of interest.

Received for publication: 11 August 2011.

Accepted for publication: 11 October 2011.

This work is licensed under a Creative Commons Attribution NonCommercial 3.0 License (CC BYNC 3.0).

(C) Copyright K. Glavind et al., 2011

Licensee PAGEPress, Italy

Urogynaecologia 2011; 25:e11

doi:10.4081/uij.2011.e11

again and weighed to obtain the defatted dry weight (DDW). The hydroxyproline content was measured after acid hydrolysis ${ }^{11}$ and used as an estimate of the collagen content.

\section{Results}

During the testing two samples from the hysterectomy group were lost due to laboratory problems leaving 13 patients in the hysterectomy group and 15 patients in the rectocele group. The mean age of the hysterectomy group was 45.4 years (31-51 years) and of the rectocele group 57.4 years (41-73 years). Mean parity was 1.7 (1-4) and $2.3(0-3)$, respectively. Moreover the mean BMI of the hysterectomy group was 26.3 and of the rectocele group 27.2.

All patients in the hysterectomy group were operated because of fibromyoma uteri. In the rectocele group 7 out of 15 patients had a previous hysterectomy ( 2 vaginal hysterectomies and 5 abdominal hysterectomies). One patient had a previous Manchester operation. Three patients were stadium III prolapse and 13 patients stadium II prolapse. Three patients were operated with both an anterior and posterior colphorrhaphy. The concentration of collagen (Figure 2) was much higher in the hysterectomy group compared to the rectocele group (67.5 vs $47.5 \mathrm{mg}$ collagen per mg DDW).

Data from the mechanical testing is shown in Figures 3 and 4. The maximum load was higher in the hysterectomy group compared to the rectocele group (13.2 N vs $7.7 \mathrm{~N})$, whereas the stiffness was lower in the rectocele group 
compared to the hysterectomy group ( $36.9 \mathrm{~N} v \mathrm{~s}$ $19.1 \mathrm{~N}$ ). When, however, the maximum load was corrected for collagen content (relative strength) there was no difference between the groups (Figure 5).

\section{Discussion}

Confusion concerning the terminology of the structure between the rectum and the vagina in the female patient has existed for years.
Some authors name it Denonvilliers' fascia, some the rectovaginal septum and others the rectovaginal fascia. ${ }^{9}$ We choose to name it the rectovaginal fascia recognizing that we consider it to be a true fascia. No previous studies have investigated the mechanical properties of the rectovaginal fascia. Rubod et al. studied the mechanical behaviour of vaginal tissue in five patients with POP and found the tissue to be hyperelastic with a large deformation. ${ }^{12}$ Cosson et al. studied the strength of different pelvic ligaments and found great variability between individuals and between different

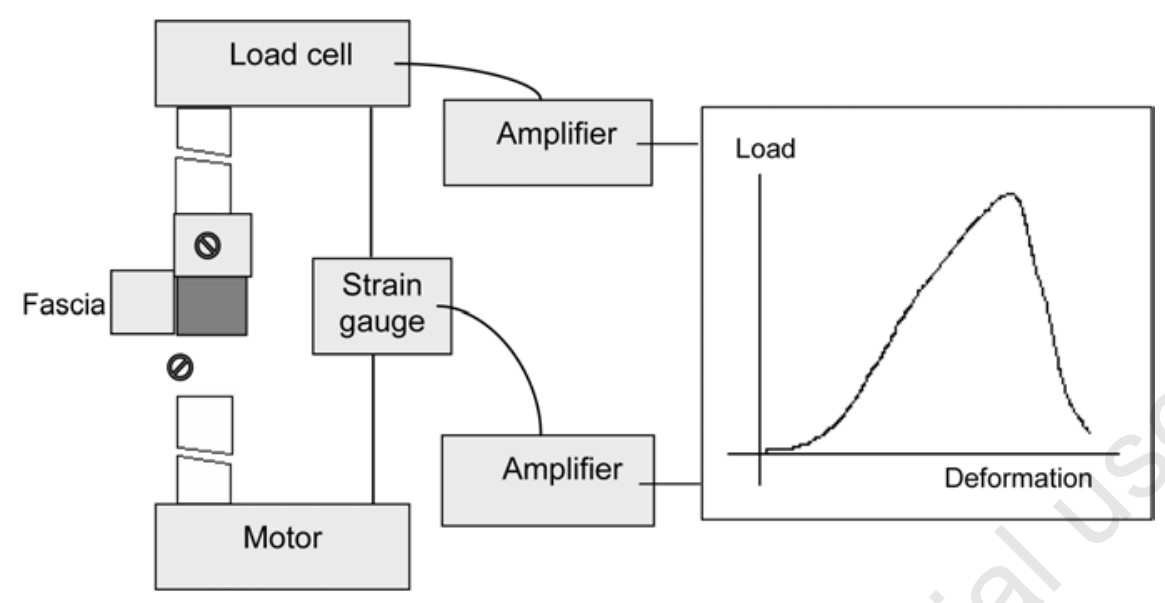

Figure 1. Materials testing machine.

\section{Collagen concentration}

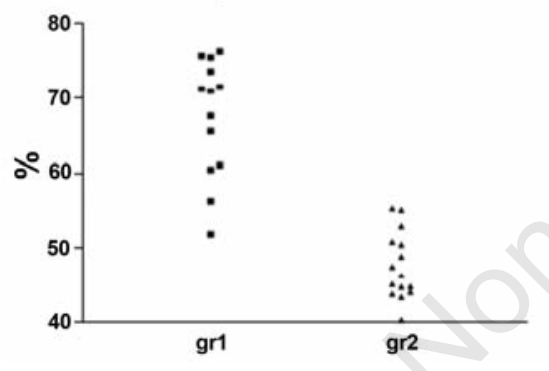

Figure 2. Concentration of collagen in the abdominal fascia (group 1) and the rectovaginal fascia (group 2).

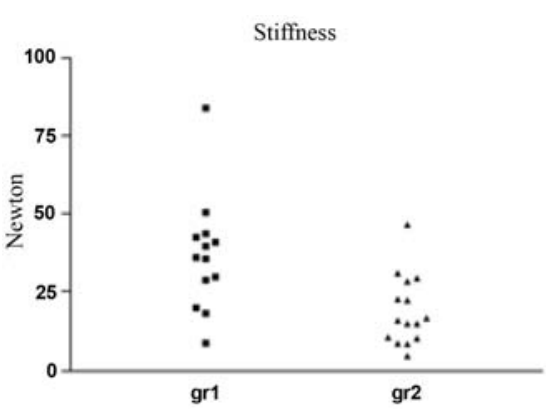

Figure 4. Stiffness of the abdominal fascia (group 1) and the rectovaginal fascia (group 2).

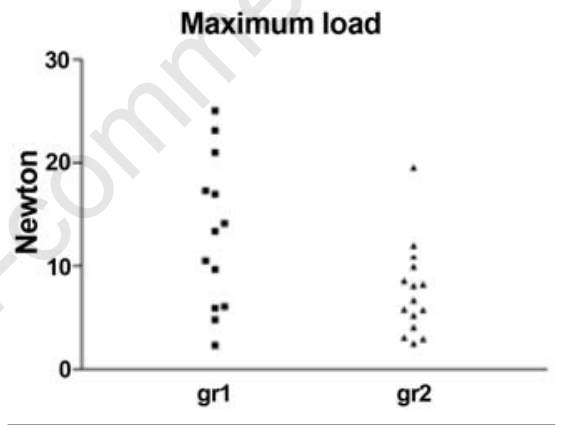

Figure 3. Mmaximum load of the abdominal fascia (group 1) and the rectovaginal fascia (group 2).

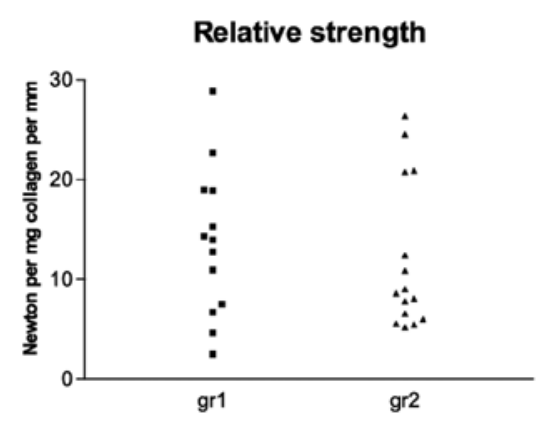

Figure 5. Relative strength of the abdominal fascia (group 1) and the rectovaginal fascia (group 2). types of ligaments in the same patient. Minimal values were around $20 \mathrm{~N}$ and maximal values at $200 \mathrm{~N}$, the vertebral ligaments being the strongest and the sacrospinous ligament the weakest. They did not study the rectovaginal fascia. This study was performed on cadavers. $^{13}$

Testing of the abdominal fascia and the rectovaginal fascia shows a significant difference in mechanical strength of the tissue. If, however, the strength was corrected for collagen content there was no difference between the two groups. This indicates that the quality of collagen is comparable between the groups, but there is a difference in the amount of collagen per defatted dry-weight. A possible explanation for the difference in collagen concentration between the groups is that preparation before testing left some non-collagenous tissue in the rectovaginal specimen, while the abdominal fascia was easier to prepare because of its well-defined nature. The difference in collagen concentration could also be explained by a higher proportion of elastin in the rectovaginal fascia. This would reduce the collagen concentration and could possibly partly explain the tendency towards increased strain in this group. We have unfortunately not measured the content of elastin.

The concentration of collagen in the abdominal fascia was around $67 \%$ and in the rectovaginal fascia around $50 \%$. In comparison the concentration in rat tail tendon is $83 \%,{ }^{14}$ and in human tensor facia lata the concentration is $94 \%{ }^{15}$ We would not expect the concentration in abdominal fascia or the rectovaginal fascia to be at the level of tensor fascia lata, but the concentration is still much higher than in many other tissues such as colon $(18 \%)^{16}$ and striated muscle (5-10\%). ${ }^{17}$ In fact the concentration found in our study is much too high to represent anything else than fascia tissue. It has been speculated that the structure adapted in the site-specific repair of rectoceles should be adventitia of the vaginal wall together with a fibromuscular part of the wall of rectum. ${ }^{5}$ These layers of tissue would, however, not contain the concentration of collagen found in our study, neither would there be a reproducible pattern of mechanical strength tests with this tissue. The clinical implications of the existence of a fascia between vagina and rectum is that a rectocele or enterocele should be considered a defect of some kind in the fascia which can be surgically treated. We find that this study has added further evidence to the existence of a distinct rectovaginal fascia.

\section{References}

1. Richardson AC. The rectovaginal septum revisited: its relationship to rectocele and 
its importance in rectocele repair. Clin Obstet Gynecol 1993;36:976-83.

2. Glavind K, Madsen H. A prospective study of the discrete fascial defect rectocele repair. Acta Obstet Gynecol Scand 2000;79:145-7.

3. Milley PS, Nichols DH. A correlative investigation of the human rectovaginal septum. Anat Rec 1969;163:443-52.

4. Cundiff GW, Weidner AC, Visco AG, et al. An anatomic and functional assessment of the discrete defect rectocele repair. Am J Obstet Gynecol 1998;179:1451-6.

5. Kleeman SD, Westermann C, Karram MM. Rectoceles and the anatomy of the posterior vaginal wall: Revisited. Am J Obstet Gynecol 2005;193:2050-5.

6. Ludwikowski B, Hayward IO, Fritsch H. Rectovaginal fascia: An important structure in pelvic visceral surgery? About its development, structure and function. $\mathrm{J}$ Pediatr Surg. 2002;37:634-8.

7. Leffler KS, Thompson JR, Cundiff GW, et al. Attachment of the rectovaginal septum to the pelvic sidewall. Am J Obstet Gynecol
2001;185:41-3.

8. Nagata I, Murakami G, Suzuki D, et al. Histological features of the rectovaginal septum in elderly women and a proposal for posterior vaginal defect repair. Int Urogyn J 2007;18:863-8.

9. Liang J, Lai H, Cheng K. Laparoscopic dissection of Denonvilliers' fascia and implications for total mesorectal excision for treatment of rectal cancer. Surg Endosc 2011;25:935-40.

10. Andreassen TT, Oxlund $H$. The influence of experimental diabetes and insulin treatments on the biomechanical properties of rat skin incisional wounds. Acta Chir Scand 1988;154:623-6.

11. Woessner Jr JF. Determination of hydroxyproline in connective tissues. In: DA Hall (ed.) The Methodology of Connective Tissue Research, pp 227-233. 0xford, Joynson-Bruvvers Ltd., 1976.

12. Rubod C, Boukerrou M, Brieu M, et al. Biomechanical properties of vaginal tissue: preliminary results. Int Urogynecol J 2008;19:811-6.
13. Cosson M, Boukerrou M, Lacaze S, et al. A study of pelvic ligament strength. Eur J Obstet Gynecol Reprod Biol 2003;109:80-7.

14. Danielsen CC, Andreassen TT. Mechanical properties of rat tail tendon in relation to proximal-distal sampling position and age. J Biomechanics 1988;21:207-12.

15. Derwin KA, Baker RA, Spragg RK, et al. Regional variability, processing methods, and biophysical properties of human fascia lata extracellular matrix. J Biomed Mater Res 2007;84A:500-7.

16. Seyer-Hansen M. Andreassen TT, Christensen H, Oxlund H. Effects of experimental diabetes and growth hormone administration on the strength of colonic anastomoses in rats. Eur Surg Res 1999;31:419-28.

17. Andersen NB, Andreassen TT, Ørskov H, Oxlund H. Growth hormone and mild exercise in combination increases markedly muscle mass and titanic tension in old rats. Eur J Endocrinol 2000;143:409-18. 